\title{
The Justice Syndicate: Using iPads to increase the intensity of participation, conduct agency and encourage flow in live interactive performance
}

\section{By Dan Barnard (London South Bank University) and Kris De Meyer (Kings College London)}

\begin{abstract}
The Justice Syndicate is an interactive performance, featuring an audience who take on the role of jurors considering a difficult case. Participants receive evidence, witness testimonies and prompts to vote and discuss the case on iPads. With this practice-as-research project we sought to explore what are the most effective means of inviting people to participate; how to widen their "horizon of participation"; how to increase the intensity of interaction in order to increase the level of "agentive behaviour" of the participants; and how to create a sense of flow in participants. We found that an effective solution to the fear of experiencing or causing embarrassment is for the invitation to participate to come from a machine and for there to be no distinction between "audience" and "participants." The use of machines to stimulate interaction in the absence of live performers also proved an effective way of stimulating a high intensity of "agentive behaviour" among audience members, although it did not automatically lead to a greater feeling of agency. Applying an adapted version of Lindinger and colleagues' (2013) codification of how to stimulate a state of flow in audience members also proved effective in creating a highly immersive experience.
\end{abstract}

Keywords: interactive performance, digital performance, agency, flow, immersive theatre, interactive digital storytelling

\section{Introduction}

In 2017 we began an interdisciplinary Practice as Research project exploring interactive and immersive performance. The project was a collaboration between the authors, combining experience from the fields of drama and performance research (Dan Barnard), neuroscience and psychology (Kris De Meyer) and professional artists with a background in theatre making (Rachel Briscoe) and computational arts (Joe McAlister).

Our collaboration resulted in an interactive performance called The Justice Syndicate. In the piece 12 audience members take on the role of jurors considering a difficult case. Each juror has an iPad on which they receive evidence in the form of audio and video testimonies from 
witnesses, various documents, legal definitions and prompts to interact with each other and discuss the case. They are also asked to take part in a series of "taking the temperature votes" about the guilt or innocence of the defendant, culminating in a final decision. The piece has so far been performed over 70 times at festivals and venues across the UK and Ireland, including the National Theatre of Scotland's Citizen of Nowhere festival (Dundee), York Mediale, Sheffield Doc/Fest, Edinburgh Science Festival, Battersea Arts Centre, Random String Festival (Coventry), The Justice Museum (Nottingham), The Broadway (Nottingham), the King's Cultural Institute (London) and the Dublin Fringe Festival.

Our key research questions in developing this Practice as Research project were:

Q1. What are the most effective means of inviting people to participate during an interactive performance?

Q2. How can we widen the horizon of participation in performance (White, 2013)? How do we increase the intensity of interaction and the level of agentive behaviour (Breel, 2017)? Q3. Is it possible to design an interactive performance without live performers that facilitates in audience members a sense of immersion by stimulating a state of flow (Csikszentmihályi, 1997)?

Below we expand on why we selected these research questions.

\section{Q1. What are the most effective means of inviting people to participate during an interactive performance?}

Dan was particularly interested in exploring this question, having participated in several interactive performances in which the invitation to participate came from a human performer. He noticed that as an audience member in these situations he felt a tendency to want to please the performer or to want to "get it right." He also felt that he was picking up non-verbal clues from performers and frequently noticed himself asking follow-up or clarifying questions in response to instructions or prompts towards interaction, perhaps as a delaying tactic to postpone the moment at which he would have to act. He was acutely aware of the risk of embarrassment - either for himself or for the performer. Gareth White (2013) analyses the fear of embarrassment among audience members, noting that the actual risks in this situation, though real, are often outweighed by the perception of risk. White also cites Goffman's (1969) claim that people not only engage in “defensive practices" to save ourselves from embarrassment but that we also use "protective practices" or "tact" to protect others from becoming embarrassed.

\section{Q2. How to widen the horizon of interaction and increase the intensity of interaction?}

Gareth White proposes the metaphor of a 'horizon of participation" "in which audience members perceive the range of behaviours through which they are invited to participate in a performance" (White, 2013 p.57). He goes on to claim that "horizons of participation belong to individual participants, but are shaped by procedural authorship" (White, 2013 p.62). We were interested in how we might widen audience members' horizons of participation in a clear, simple and unthreatening manner.

One of our motivations in embarking on this project was that Dan had attended several supposedly interactive performances in which levels of interaction were in fact minimal or in 
which he did not feel a strong sense of agency within the performance. In some of the more successful examples, his illusion of agency and then his realisation that it did not really exist was in fact part of the meaning that the artwork sought to convey. For example, in Coney's Adventure 1 (2016), participants were led to believe that they had a choice about what to do with a memory stick that allegedly had the ability to "quake" and disrupt the financial markets. However, the same outcome occurred, irrespective of the participants' choice, because of a plot twist in which it was revealed that the two characters in the piece, who had seemed to be on opposite sides, were in fact in league. The piece gave participants the illusion that they had agency when in fact they did not; a powerful comment on the role of the individual in face of the global financial markets.

Notions of agency within interactive performance are highly contested, so we would like to outline some of our reflections on agency and where they originate. Firstly, Clare Bishop (2012) has strenuously argued against the unthinking equation of participation and democracy: just because an audience member has (or perceives themselves to have) agency, this is not automatically a good or empowering thing. Secondly, we agree with Astrid Breel (2017) that agency is something that people already have; it is patronising to assert that the "procedural author", to borrow Gareth White's (2013) phrase, in designing an interactive performance can give or enable agency. It is more appropriate, as Breel asserts, to speak of "conducting" agency. We also believe, with White and Breel, that within the realm of participatory performance, agency is primarily an aesthetic, rather than an ethical consideration. Our motivations for exploring it were therefore mostly aesthetic. This article, however, is not concerned with theorising agency but rather with exploring the practical process of conducting it and the implications that has.

\section{Q3. How to stimulate a sense of flow?}

Mihaly Csikszentmihalyi's (1997) concept of 'flow', a state of complete absorption in the activity at hand, has influenced thinkers in a range of fields. Csikszentmihalyi explains that he "started to study people who seemed to be doing things that they enjoyed but were not rewarded for with money or fame' such as chess players, rock climbers, dancers and composers (Csikszentmihalyi, 1997). He found that they were motivated by the quality of experience that they felt when they were involved with the activity, an optimal experience which he named Flow. This optimal experience was produced when people were engaged in activities that stretched their capacity and involved an element of novelty and discovery, resulting in "an almost automatic, effortless, yet highly focused state of consciousness" (Csikszentmihalyi, 1997). He found that nine main elements were mentioned over and over again to describe such an experience:

1. There are clear goals every step of the way

2. There is immediate feedback to one's actions

3. There is a balance between challenges and skills

4. Action and awareness are merged

5. Distractions are excluded from consciousness

6. There is no worry of failure

7. Self-consciousness disappears

8. The sense of time becomes distorted

9. The activity becomes autotelic 
Lindinger and colleagues (2013) adapted Csikszentmiyalyi's components of achieving flow to an interactive performance context, arguing that flow is best produced when audience members have a free choice to participate; have clear goals and control; and receive immediate and direct feedback. It also requires a balance of challenge and skills (so participants are adequately stretched); phases for pause and learning; and creative expression within a clear artistic frame (ibid.).

\section{Materials and Methods}

We undertook an iterative design process (Dieli, 1989) which began with setting our research objectives and then sharing our collective knowledge (e.g. Kris sharing principles of individual and group psychology; Dan sharing insights from drama and performance research; Joe sharing ideas about what technologically had been done and could be done; and Rachel sharing principles from her playwriting experience). In our ideation process of exploring how we might achieve an artwork that effectively invited audience members to participate, widened their horizons of participation, increased their intensity of interaction and agentic behaviour, and stimulated a sense of flow in audience members, we arrived at the idea of creating a piece of "actorless performance" in which all of the material was delivered to the audience on iPads. We explain more about this in the Results section.

We also wanted to create an experience in which audience members played as close a role to themselves as possible. We settled on a jury format as it is one of the few real-life situations in which a group of strangers come together to make an important decision. We made this decision because of a principle coming from Rachel's interactive work that it helps to invite people into an interactive experience with a frame that they recognise - for example a dinner party, a jury etc. - and then explore complex ideas as the piece develops.

Having arrived at the idea of creating an experience in which audience members have iPads and are playing the role of jurors, we embarked on an iterative design process that incorporated several phases of user testing.

The design process involved four separate but inter-related creative processes:

a. Structuring the overall experience: when and in what form would audience members receive evidence, and when should they vote and discuss?

b. Writing the software that enables participants to receive the content, vote, see voting results and get prompts to discuss. This also involved elements of machine learning to decide which participants to give certain tasks during the performance.

c. Writing the content of the evidence itself; audio or video recording the witness testimonies; and generating authentic-looking documents.

d. Devising a "debrief session" to take place after the interactive performance, in which participants are invited to set aside the content of the jury case itself and reflect on their participation and experience of the performance.

While every creative process is different, this process was unlike any that the collaborators had engaged in before because of the specific affordances of the iPads and the opportunity for different types of content and interaction that this provides. The iPads meant that participants could engage in relatively traditional theatrical activities such as watching videos of actors giving witness statements. They could also engage in activities that are not 
conventionally expected in a theatre, such as examining forensics reports and GPS data, discussing, and voting. The design process involved a "paper prototype" phase in which a test audience experienced the case not on iPads but on a paper script, with the creative team reading the witness testimonies and doing the voting mathematics and reports manually. Following this phase, some of the evidence was tweaked to ensure that the case was less clear-cut, encouraging more debate and discussion among audience members before the final documents were created and the witness testimonies filmed.

In terms of the software development process, Joe wrote that "unusually, I left most of the technical development until after we had created the underlying narrative of the piece. This was as the specific events within the case had a significant effect on the functionality and limitations of the systems" (McAlister, 2018). The system that he went on to create was, he said, "the most bespoke and complex system I have ever created. Three iterations exist with the final completed in early 2018" (ibid.).

It might be useful to outline the structure of the resulting finished piece here to help the reader imagine the experience and contextualise some of the more detailed comments we make later.

The Justice Syndicate is experienced by twelve people at a time. When audience members assemble they are welcomed by Dan Barnard and informed that when they enter the room they may sit at any chair, that in front of them there will be an iPad and that during the piece the iPad should give them everything that they need to know and that if they have any problems with their iPad they should raise their hand and our technician, Joe McAlister, will come and help them - but apart from that, neither Joe nor Dan are allowed, nor qualified to advise them on any points of law - that the decision is theirs alone. They are also told that after the 90 minute performance, there will be a debrief of about half an hour. They then enter the room and sit down. In the room there is a table with 12 chairs and 12 iPads. At each place there is a placard with a juror number (juror 1, 2, 3 etc), an iPad, a reporter's notepad and pen and a glass of water (see Figure 1). Once everyone has taken a seat, there is an on-screen tutorial about how to use the iPads during the piece and then the piece itself begins with a "BBC London" news story outlining the key details of the case - that a renowned childhood cancer surgeon, Simon Huxtable, has been accused of sexual assault by Sally Hodges, a "single mother of two" from Kingston-upon-Thames. They then read a browsing history of the defendant (which features doctor-patient pornography, an article about forced anaesthesia and various other web pages. Following this, they read an article about his stellar career as a surgeon. They see GPS data which shows how long Simon Huxtable's mobile phone was at Sally Hodges' house on the evening in question. Each juror is then asked to read aloud one sentence from the closing statements for the defence and the prosecution (partly to give a flavour of the key arguments on each side and partly so that everyone has spoken in the group in advance of the first group discussion. They then engage in the first of a series of "taking the temperature" votes, in which they are invited to vote on their current impression of whether the Defendant is guilty or not guilty. After each of these votes, audience members are informed of how many people voted for guilty or not guilty. 
In the next section of the piece, they watch or listen to a series of witness testimonies, performed by actors and watched on the iPads during the piece. The first is from Simon Huxtable's wife, Holly, the second is an audio recording of a mother of one of Simon's patients (it is a positive character witness statement), Emma and the third is Sally Hodges' own account of the evening in question. After this, they watch a video interview with a (real) expert on the relationship between sexual fantasy and real-world actions, Dr Alex Dymock. There then follows a glossary of the meaning of various legal terms (rape, assault by penetration, sexual assault, reasonable doubt and majority verdict). They then have the first of a series of discussions about the case (this one is 3 minutes long). During each of the discussion sections, various of the documents including the glossary are available for audience members to return to if they wish. Following this, they have the second "taking the temperature" vote.

In the next section of the piece, two audience members read aloud an online BDSM chat between Simon and someone called Gail and then there are two video testimonies (again performed by actors). The first is from a former friend of Sally's about her past and the second is an account by Sally's sister of how she found out about the incident. There then follows a written account of the evening from Simon and a video interview with (real) expert on data about the reporting of sexual crimes, Jan Bowden. Following this, audience members again discuss the case (for five minutes this time) and again vote in a "taking the temperature" vote. After this, they see a forensics report about some blood found on Sally Hodges's coffee table (presented in corroboration of her account) but the report can only confirm that the blood sample is male, not whether or not it matches Simon Huxtable's. This is followed by a video witness statement from Simon Huxtable (performed by an actor) and a further discussion section (lasting seven minutes). Two audience members selected at random then read the closing statement for the Defence and the closing statement for the prosecution. There is then a further seven minutes of discussion and then a "final" vote. If this vote is unanimous, the piece ends here. If it is not unanimous, audience members are given a further three minutes of discussion, followed by another vote. With this vote, they have to reach a 10/2 majority. If they do not, there is a final 3 minutes of discussion and one last vote. If this does not reach a 10/2 majority, a verdict of acquittal is given.

The verdict is presented on audience members' iPads and then each audience member is given an A3 "newspaper," the front page of which reports on their verdict (there is a "guilty" and "not guilty" version). The debrief section of the experience then begins. The debrief is normally co facilitated by Dan Barnard and neuroscientist Dr Kris de Meyer. During this debrief, audience members are invited to reflect on their decision-making process, as individuals and as a group, and Kris shares some of the key psychological principles at play during the piece and data about the voting behaviour of previous audiences (we have now done over 70 performances) that supports this. They are then invited to ask any questions they have about the piece, at which point audience members often share reflections about the law and legal processes, or wider societal issues raised in the piece. 


\section{Results}

\subsection{Invitation to participate}

White (2013 p.73) writes that "when participatory performance invites performances from audience members, it presents special opportunities for embarrassment." In the process of designing The Justice Syndicate we were acutely aware of this and sought to design the piece in a way that generally minimized embarrassment. While exploring possible solutions to our research questions we began to wonder whether the problems of embarrassment might be partly circumvented by creating a situation in which the invitation to participate comes not from a human, before whom we might fear embarrassment either for ourselves or for them, but from a machine which, we assume, cannot feel embarrassed itself and before which we might not fear embarrassment. Additionally, one cannot ask a machine follow-up questions as a way of stalling and avoiding the moment of interaction (and potentially heightening this anxiety through delay).

The fear of embarrassment can also relate to the fear of performing in front of others. We went some way to assuaging this fear by creating a context in which it was clear that everyone would be a participant, and no one would be a passive observer. By creating the sense that everyone is in the same situation, the fear of embarrassment is reduced. The physical set up of the situation (see Figure 1) makes it clear that there is no participant/ audience divide and that all participants have essentially the same role. Each participant has a sign in front of them with their juror number on, which helps to make clear that everyone will participate. Additionally, within the first ten minutes of the piece, everyone is required to read a paragraph (extracts from statements from the counsel for the Defense and the counsel for the Prosecution) which makes that even clearer. 


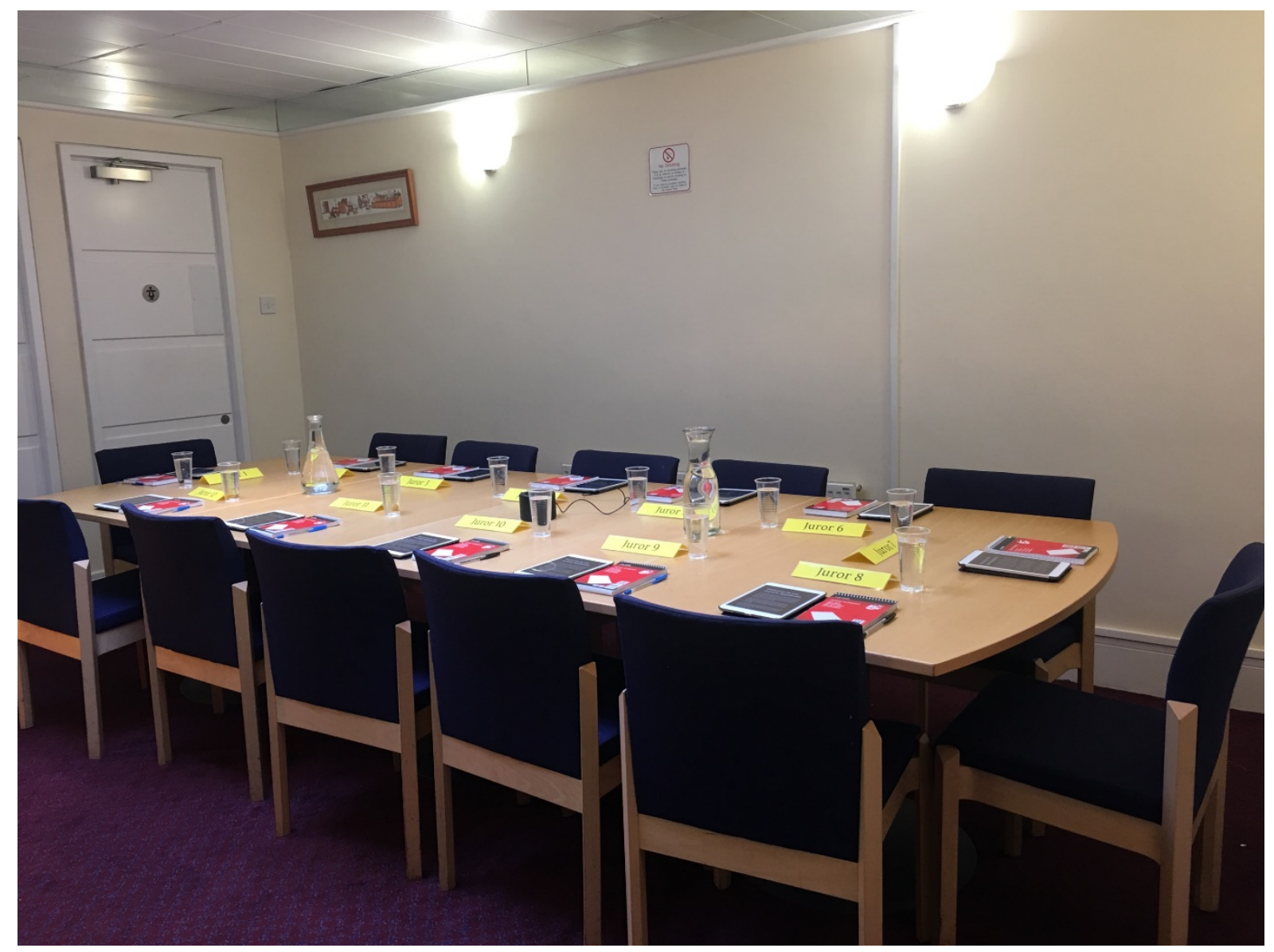

Figure 1: Room setup for the Justice Syndicate, in the jury deliberation room at Dundee Sherriff's Court for the National Theatre of Scotland's Citizen of Nowhere Festival (November 2018).

Later in the piece, however, we intentionally designed a section in which participants could experience embarrassment, leveraging embarrassment as part of the aesthetic and affective experience. At this point in the piece, two participants are selected by the software that controls the piece and required to read out a sexually-explicit BDSM chat between the defendant and someone that he is chatting with online. This often produces (nervous) laughter and participants sometimes comment to each other afterwards on the awkwardness of it. We considered the possibility of having this just as something that participants read in silence, but the more visceral experience of hearing or speaking it aloud serves at that point to nudge some participants towards a guilty verdict, in a way that can enhance the drama of a split vote and the intensity of later debates.

The idea that one feels less embarrassed in front of a machine plays out in an additional way during the performance. In contrast to a real jury, where jurors publicly declare their opinion about the guilt or innocence of the defendant, The Justice Syndicate invites participants to anonymously vote via their iPads. This mechanism allows participants to know how the group is leaning, without experiencing public embarrassment towards the group. Indeed, it may be stressful to publicly come out with a position that goes against the prevailing group sentiment, or that in some way falls foul of what one believes to be the cultural norms of the moment. This is reminiscent of, for instance, the idea of the "shy Tory" phenomenon in the UK in which people who are embarrassed to say that they are voting 
conservative to a person in an opinion poll, nevertheless vote conservative when they are in the anonymous situation of the polling booth (Curtice, 1997). In some performances, this ability to vote anonymously created a fascinating dynamic in which the conversation was dominated by a set of arguments leading in one direction (e.g. that the defendant was not guilty) but the votes repeatedly showing something different (e.g. that the defendant was guilty). On at least one occasion, this was remarked on by the participants, who asked those who had been speaking less but voting differently to share their views.

It is important to caveat the remarks about the iPads making people less embarrassed (i.e. more comfortable) by noting that some people are more comfortable using iPads than others. This was something that we observed in participants, despite Joe's considerable efforts to make the user interface as intuitive as possible. A few people experienced moments of initial confusion or discomfort, particularly if they had never used a tablet before. It was not always older people who expressed these difficulties; sometimes they were people who might conventionally be considered "digital natives" (Prensky, 2001).

\subsection{Horizon of participation, intensity of interaction and agentive behaviour}

\subsubsection{Shaping the horizon of participation}

As procedural authors, we shaped the horizon of participation in three ways.

a. By making the invitation to participate very clear in the marketing copy, describing it as "playable theatre" and concluding with the question "How will you vote?"

b. By gradually widening the horizon of participation as the piece develops. It starts with two randomly selected participants reading aloud from a script on the iPads to introduce the case, but most of the first part is spent looking at evidence, watching witness testimonies or occasionally speaking pre-scripted sentences displayed on the iPads. In the latter part of the piece, there is more and more unscripted free discussion of the case. Thus, the intensity of participation increases and becomes less structured as the piece progresses, allowing participants to "warm up" and become more and more active over the 90 minutes of the experience.

c. Finally, we designed the experience so that the longer it goes on, the more participants want to take part. This is achieved by asking participants to vote early on in "taking the temperature votes", encouraging them to take a position; by dripfeeding information so that participants become increasingly invested in the group reaching what they consider the "correct" verdict; and by showing them the voting ratio so that they knew if there are still other participants they need to win over to their side in order to achieve a (unanimous) verdict.

One way to understand this increasing engagement is with Aronson and Travis's (2015) Analogy of the Pyramid (see Figure 2): as long as participants are undecided, it is as if they are at the tip of a "decision pyramid". Once they make a decision - often tentatively at first - this amounts to a step off on one side of the pyramid. This step triggers a psychological process of self-justification: "I made the right choice because...". This, in turn, makes more likely that subsequent actions (e.g. defending their choice publicly in the group) go in the same direction. The further they step down the sides of the pyramid, the more people convince themselves of the correctness of their decision, and the more they may feel the need to convince others who do not yet agree with them (Festinger, 1950). 
Indeed, in the final twenty minutes of the piece we frequently observe an increase in the amount, speed and volume of speaking in the discussions between audience members, suggesting that the more they vote and argue, the more passionately they come to believe that their decision is the correct one. Whether the group reaches a consensus or remains divided depends on the group dynamics, and on the strength of individual convictions among the two "sides" that usually develop at the start of the piece.

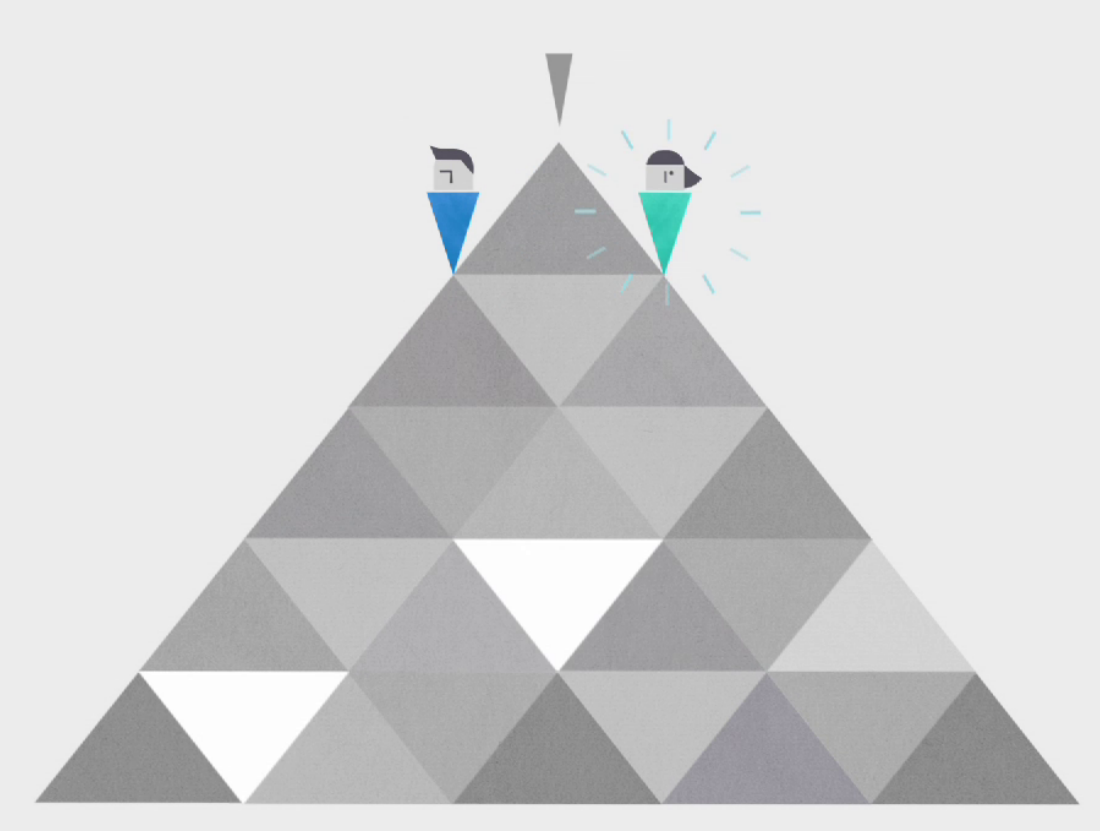

Figure 2: The Analogy of the Pyramid (Tavris and Aronson, 2015). An initial choice - which is often triggered by the first "taking the temperature" vote - amounts to a step off on one side of the pyramid. This first decision sets in motion a cycle of self-justification which leads to further action (e.g., taking a public stance during the group discussion) and further selfjustification. The deeper down participants go, the more they can become convinced and the more the need arises to convince others of the correctness of their position.

\subsubsection{Observation of agentic behaviour in audiences}

We were present at most performances of the piece (at the tech desk) and observed a range of "agentic behaviours" (Breel, 2017) among audience members, particularly speaking and voting. Speech behaviours divide into three broad categories: asking questions to clarify their understanding or memory of the evidence; expressing their opinions about the evidence; and seeking to persuade others of their views. Clarifying questions tend to appear more frequently in the early discussion rounds, whereas expressing views and particularly attempts at persuasion are more present in the later discussion rounds. We frequently observed that as the piece enters the final rounds of discussion, the frequency and volume of speech increases, especially in performances where the group is divided in their votes.

Audience members are instructed to vote on their iPads at various points during the performance, initially in the form of "taking the temperature votes" and later in votes aimed at reaching a final verdict. At some stages, they are also able to vote for the option to evict another juror and then for who (if anyone) to evict. The first of these eviction votes is anonymous and the second is public so that people can see who wants to vote them off. 
Breel (2017) makes a useful distinction between agentive behaviour and an experience of agency, noting that participants in interactive performance often exhibit agentic behaviour without experiencing a sense of agency or, conversely, experience a sense of agency without exhibiting very much agentic behaviour (Breel, 2017). Participants in The Justice Syndicate experience a sense of agency that is facilitated through the use of technology. The iPads give immediate feedback about the voting (Figure 3).

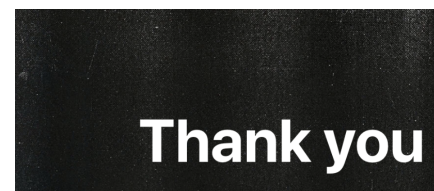

\section{These are the results.}

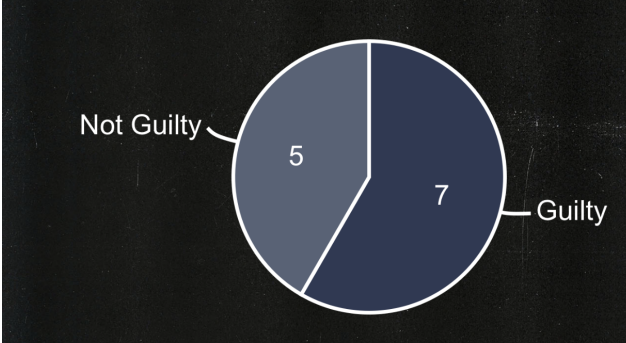

Figure 3: Screenshot of the "voting results" on one of the iPads in The Justice Syndicate

As well as lending the votes a sense of agency, these also give participants the impression that they can influence each other in the discussion when they see that some votes shift from one round to the next. This sense of agency is enhanced through analogue means too: at the end of the performance, participants receive a copy of "Tomorrow's News" a newspaper with the front page reporting either "Doctor guilty of sexual assault" or "Doctor acquitted of sexual assault" (see Figures 4 and 5). In many performances, someone asks whether there is a newspaper for the alternative result and respond appreciatively when they discover that there is, as it indicates that the decision really was the group's to make. 


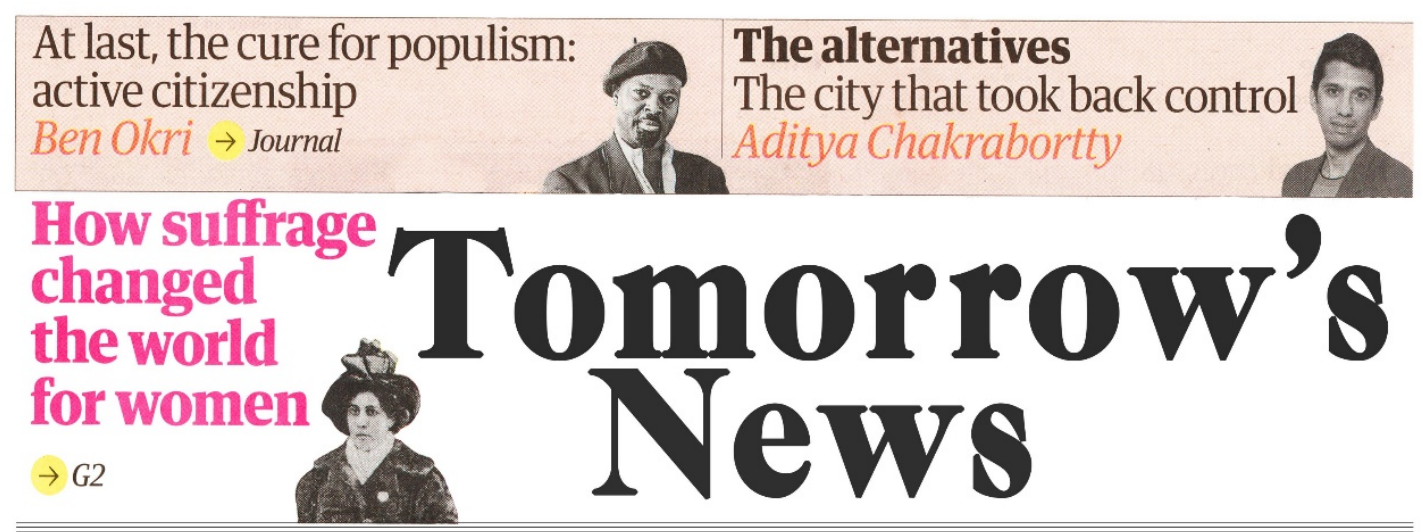

\section{Doctor guilty of sexual assault}

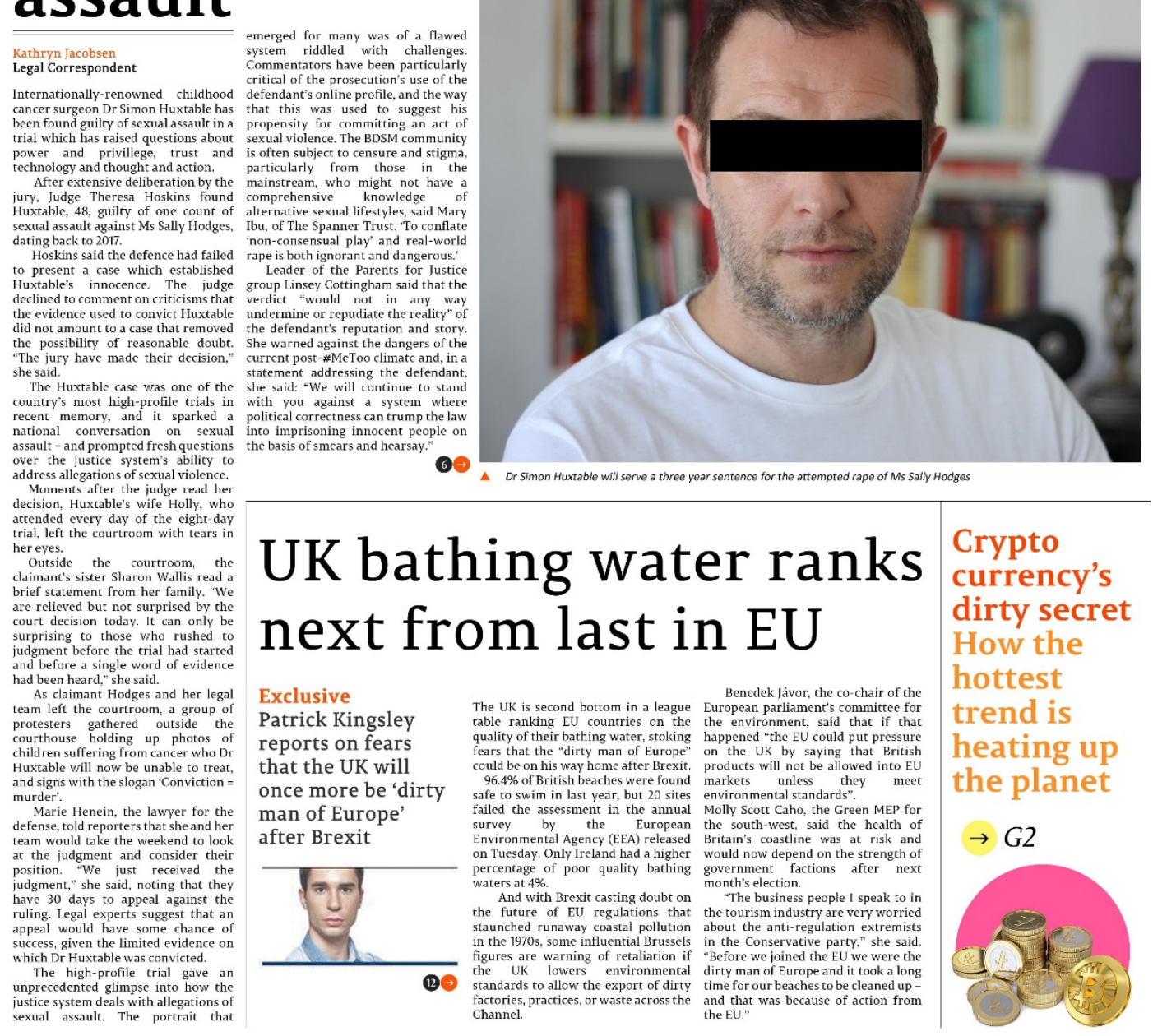

Figure 4 Newspaper given to participants if the final vote produces a guilty verdict. 


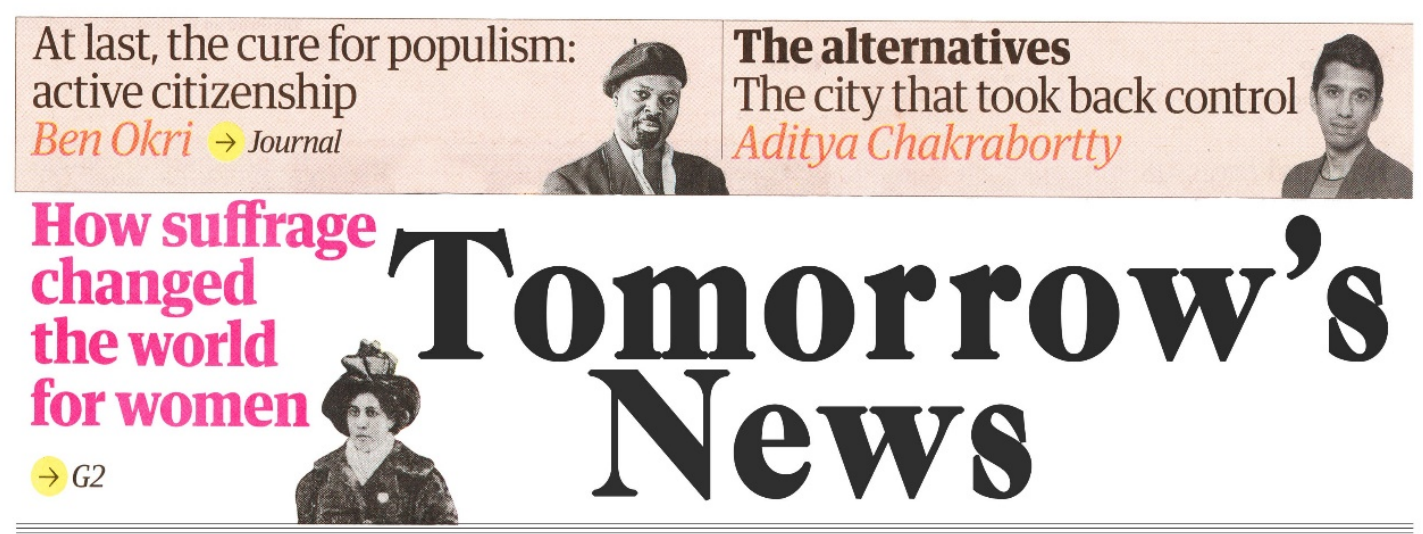

\section{Doctor acquitted of sexual assault}
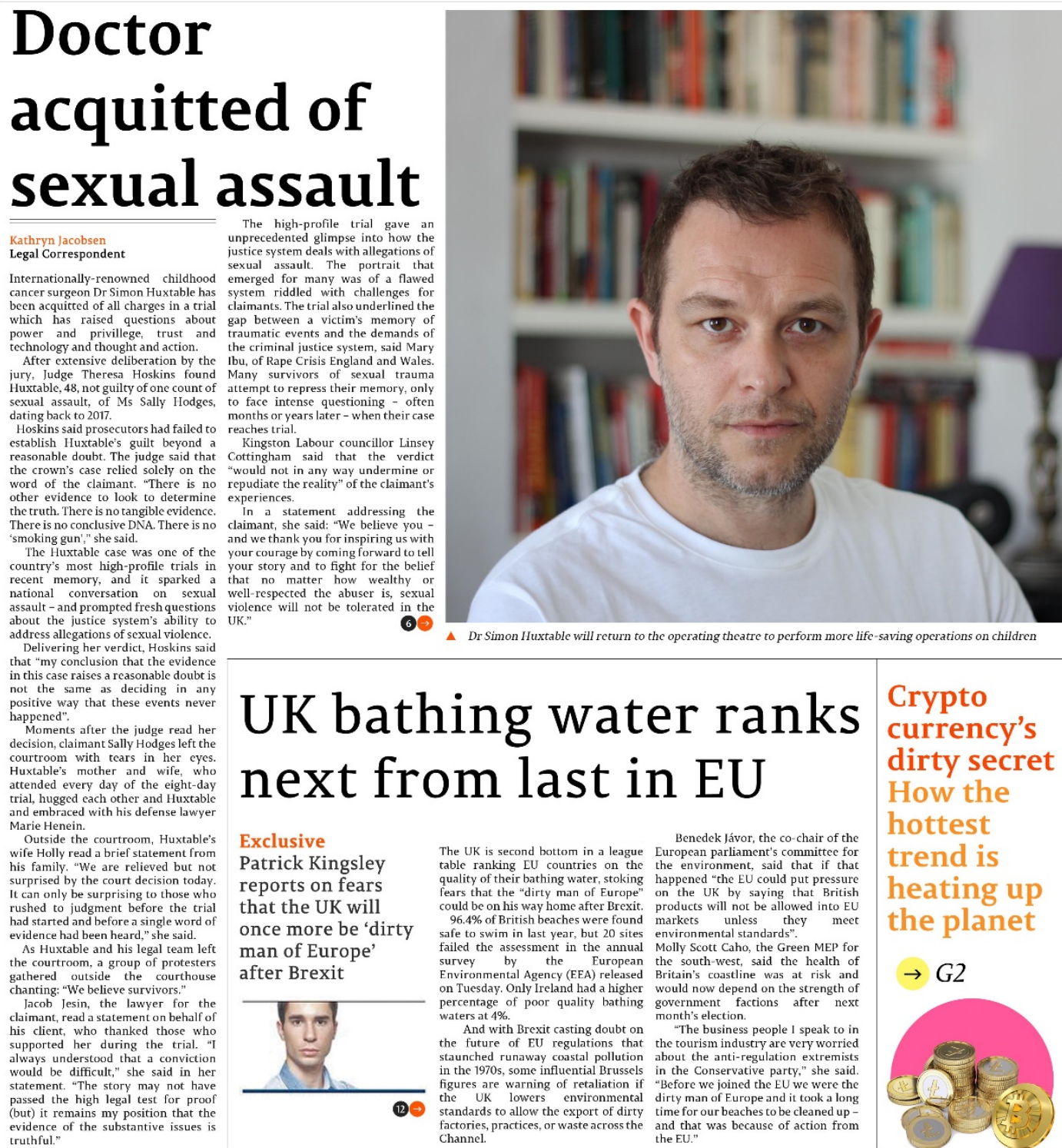

Dr Simon Huxtable will return to the operating theatre to perform more life-saving operations on children

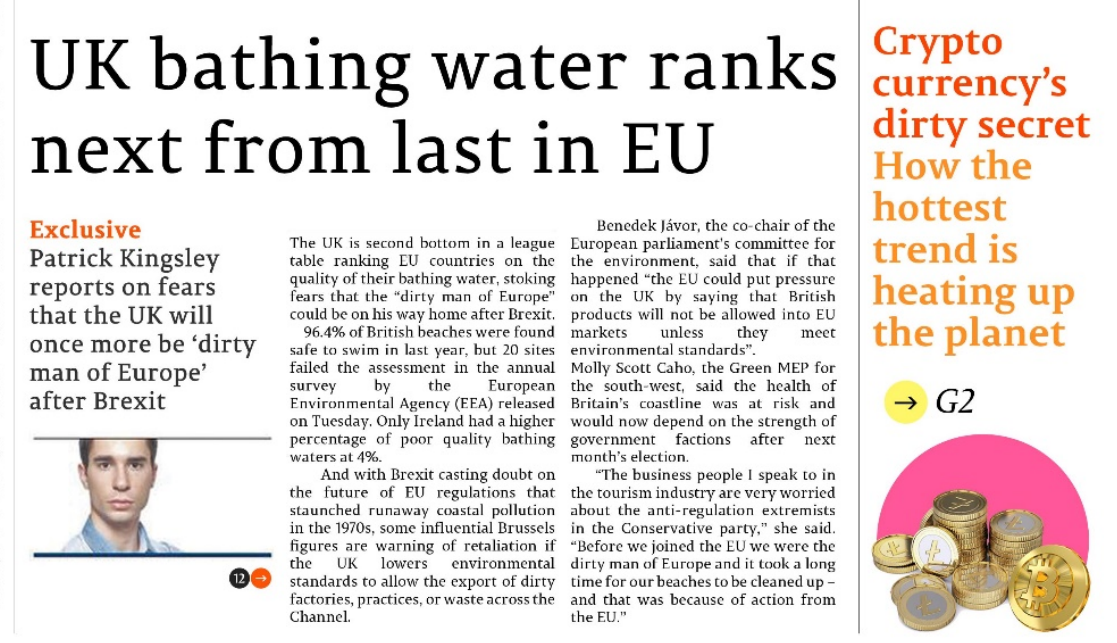

Figure 5 Newspaper given to audience members if the final vote produces an acquittal.

We should caveat these remarks on agency by noting that there are limitations on the agency of audience members. Some of these limitations mimicked limitations on agency in 
the real world, such as the way in which audience members are forced to make a binary choice of guilty or not guilty. When the piece was performed in Scotland (in Dundee as part of National Theatre of Scotland's Citizen of Nowhere festival and in Edinburgh as part of Edinburgh Science Festival), audiences observed that in Scottish law there is a third option for juries ("not proven") and that this case helped them to see why that option was a useful one to have. Audiences in many performances expressed frustration at the nature of this binary choice, wishing that they could wait, ask for the police to do additional checks, cross examine witnesses themselves or request that the defendant be released and then monitored. None of these are options that juries have in the real world. Other limitations on agency, however, related to the conditions of the performance. If audience members could not reach a unanimous decision, two additional rounds of discussion and voting would be added to the show. If there is still not a majority of 10 to 2 (a ratio that is permitted in legal situations if a jury cannot reach a unanimous verdict) after these additional rounds, then a verdict of acquittal is given. In a real jury situation, discussions would continue for hours or sometimes days until a decision is reached, but in a theatrical context it is necessary to place time limits on the length of a performance. Finally, the decision made by audience members has no impact in the real world so the agency that they experience is limited to the fictional context of the performance. It is important to always be cautious when making claims for the level of agency in interactive performance even when one is claiming (as we are here) that a particular piece has more agency than most examples of the genre.

A further interesting observation about agency in the performance is that despite engaging in a great deal of agentive behaviour, participants that we spoke to after the performance often claimed that they did not always feel a sense of agency. This mirrors Breel's (2017) findings that audience members can often display a great deal of agentive behaviour without feeling a sense of agency or, conversely, feel a strong sense of agency without displaying much agentive behaviour. In the case of The Justice Syndicate, this seems to be the case for two key reasons:

1. Often people's agentive behaviour does not achieve the desired results. In other words, they try to persuade the rest of the group of the guilt or innocence of the defendant, but the vote continues to go against them.

2. During the debrief session that follows the experience, Kris explains relevant insights from the study of group and individual decision making and how they may play out during the performance. This causes some people to experience a loss of agency at first because they realise that their reasoning, conscious mind may have had less influence on their own behaviour and their ability to influence others than they believed. Paradoxically, awareness of the nonconscious influences of group pressure and individual biases may be the first step to experience more genuine agency in the real world, because the increased awareness gives one a choice to break with otherwise automatic or habitual reactions to challenging situations.

\subsection{Design to encourage a sense of flow}

In creating the procedural design of The Justice Syndicate, we attempted to achieve a state of flow in participants (Csikszentmihályi, 1997). We will first discuss the components for achieving flow in interactive performances, as outlined by Lindinger and colleagues (2013). Following that, we provide evidence of the immersion that follows from or is a sign of being 
in a state of flow. Finally, we will compare the sense of immersion during the experience with the process of self-reflection during the debrief session.

\subsubsection{Components of flow}

\section{A. Free choice to participate}

As noted above, the marketing copy made clear that the piece was interactive. The door remained unlocked throughout the piece and audience members were free to leave when they pleased. In only 1 performance out of 50, an audience member left (within the first five minutes - perhaps once they realised how interactive it was). We would argue that there is a tension between giving people a free choice about whether to participate and avoiding embarrassment because, as we argued above, one way to avoid embarrassment is to ensure that everyone participates, and no one is a passive observer.

\section{B. Clear goals and control}

Participants in The Justice Syndicate have a single, clear goal: to make a collective decision whether the defendant is innocent or guilty. They have an element of control because they are one of 12 people who have a vote and can attempt to persuade others to vote with them. This voting is introduced early on and repeated several times as the piece progresses.

\section{Receiving immediate and direct feedback}

The participants receive immediate and clear feedback in the series of "taking the temperature" votes that they engage in. Immediately after voting they receive a graphic representation of the number of guilty and not-guilty votes (see Figure 3), showing participants how close or far they are from making a collective decision.

\section{Balance of challenge and skills (so they are adequately stretched)}

Participants have a goal that is clear but also challenging. They have to reach a collective decision, but the evidence is conflicted and designed to elicit disagreement among players. They are also told initially they need to reach a unanimous decision, but this is adjusted to a 10 to 2 majority near the end if they are failing to agree. In addition to the challenge of the task, there is also an element of challenge in the process of understanding the case and identifying key points of similarity between the accounts of witnesses or pieces of evidence. Jane McGonigal (2011) argues that in video games a key part of player engagement and player immersion results from players being challenged, engaging in tasks that are difficult but not impossible. This is a dynamic that we sought to replicate in The Justice Syndicate.

\section{E. Phases for pause and learning}

The Justice Syndicate does not exactly include phases for pause but it does invite participants to shift between different modes, from reading and analysing evidence in silence to watching witness testimonies to discussing the case with fellow jurors. The discussion sections provide an opportunity to process the information they have encountered while the watching and reading elements provide a break from the social interaction with other participants. Clare Bishop $(2012$, p53) argues that "the contemporary discourse of socially engaged art.... is frequently characterized by an aversion to interiority and affect: it can often seem that the choice is between the social or the solipsistic, the collective or the individual, with no room for manoeuvre between the two." The procedural 
design of The Justice Syndicate aims to give participants the opportunity to manoeuvre between the two at different moments in the piece.

\section{F. Creative expression within a defined artistic frame}

The artistic frame of The Justice Syndicate is clear: participants are members of a jury. The fictional frame of a jury is one that people find very accessible and easy to grasp as they are aware of what a jury is and does from popular culture (television programmes, news stories) or from direct experience. There is a 35\% chance of adults in England and Wales being called for jury service during their lifetime and a 95\% chance for adults in Scotland (Traynor, 2016).

It might be a stretch to claim that participants in The Justice Syndicate engage in creative expression, but they do have opportunities to express their opinions and their interpretations of the evidence and of the law. It appears as if most participants argue their own position in a straightforward manner, reporting afterwards that they really "got into" the case. Occasionally, we have observed individuals take on a more creative role; e.g. by adopting a position of "we have an opportunity to right a wrong in society"; or when people attempt to take a leadership role in the piece (e.g. by taking on the role of jury foreman).

\section{G. Time}

One way in which The Justice Syndicate differs from a flow experience is in the perception of time. Whereas in a flow experience, one does not notice the passing of time, in The Justice Syndicate, participants are made acutely aware of it. The iPad screen has a moving time bar which always indicates how much time is left in a certain section. The awareness of time is especially acute in the voting and discussion sessions, when participants often express a sense of time pressure to decide or discuss something. While this sense of having not enough time to achieve something differs from a flow experience, it also differs from a traditional theatre experience, in which we might be aware of time pressure on the characters in a play but are unlikely to experience that pressure ourselves.

\subsubsection{Evidence of immersion}

A number of audience members commented on how immersed they were in the experience. One reviewer wrote: "For 90 minutes, I am totally immersed in this trial. At some point my cheeks flush, my heart starts pounding and I have to remind myself that it is just a performance" (Alier, 2019). Other audience members who have undertaken real jury duty have commented on how similar the group discussions feel to those in real-life juries. Further evidence of immersion includes the reactions of participants during the performance. For instance, there are frequent gasps and other noises of emotion when instructions to vote and voting results appear on the iPads. Participants also respond to the video testimonies in ways that indicate they have forgotten (at least temporarily) that they are watching actors play a role. One participant asked the group after watching the video testimony of the defendant: "Did you see the expressions of micro-aggression on his face?" Similar comments about liking or disliking, trusting or distrusting other witnesses indicate that participants feel boundaries fading between watching actors in a play, and the act of judging real people with personality traits, hidden motives and intentions.

While we argue that The Justice Syndicate produces an experience of immersion in audience members, we hesitate in describing it as "immersive theatre" because it does not feature 
"an all-encompassing sensual style of production aesthetic" (Machon, 2013, p.66). It also does not fit one of Machon's other definitions of immersive theatre - "that practice which actually allows you to be in 'the playing area' with the performers, physically interacting with them" (ibid.) for the simple reason that there are no live performers. It does, however, feature the "direct participation of the audience member in the work" (ibid.).

Gordon Calleja (2011) makes some useful distinctions between different types of immersion in games studies, which Machon (2013) adapts in her study of immersive theatre. Calleja describes "immersion as absorption" as following the Oxford English Dictionary (2003)'s definition of that word as "absorption in some condition, action, interest." As an example of "immersion as absorption" he cites the example of playing Tetris, which is highly absorbing but does not involve representational mimesis. "Immersion as transportation" does, however, use representational mimesis. As Calleja puts it, "Half-Life 2 presents the player not just with an engaging activity, but also with a world to be navigated." (Calleja, 2011). "Immersion as transportation requires an element of spatiality." Machon (2013) develops Calleja's (2011) discussion of immersion to distinguish between "immersion as absorption", "immersion as transportation" and "total immersion" which combines absorption and transportation and is different from the "total immersion' described by Brown and Cairns, which, according to Calleja, could just be a very intense form of "immersion as absorption (Calleja, 2011). The experience of The Justice Syndicate seems to generate "immersion as absorption" as it frequently engages the participants fully "in terms of concentration, imagination, absorption and interest; a total engagement in an activity that engrosses...the participant within its very form" (Machon, 2013, p.62). It lacks, however, the scenographic and visceral qualities or the elements of spatiality required for "immersion as transportation." One of the reasons why we did not pursue "immersion as transportation" in the creation of The Justice Syndicate was the desire to create a piece that was eminently portable and easy to tour. More significantly, though, there were artistic motivations: our main aim was not to transport our audiences but rather to provoke thought in them and to invite them (during the debrief session) to relate the experience they had during The Justice Syndicate to situations of disagreement and bias in their real lives. We therefore decided to create an experience in which they were playing as themselves (rather than as another character) in an experience that was at the smallest possible remove from their normal lives.

\subsubsection{The role of the debrief: immersion + self-reflection = experiential learning}

Another of our aims with the piece was to create an experience in which participants are highly immersed (or absorbed) and then follow that with a debrief session in which they are invited to reflect on what happened. One motivation for including the debrief is that people tend towards "naïve realism" (Ross and Ward, 1997), meaning that we have a natural tendency to think that we see the world objectively. When having group conversations as in The Justice Syndicate, this naïve realism may lead us to think that these are the only possible discussions we can have and the only correct conclusions we can draw. However, the wide range of outcomes (from unanimously guilty to unanimously not-guilty and anything in between) and the diverse discussions and group dynamics we have observed demonstrate that this is not the case. The role of the debrief is - without being didactic - to make the participants aware of these differences, and to introduce new mental tools that allow them to make sense of their experience (insights from individual and group psychology). 
When the debrief starts, the participants are asked to set aside the specifics of the case and, in a facilitated discussion, they become aware of how their experience of taking part relates to (and may differ from) that of other members of the group. Through input from the facilitators, they are also able to compare their group's experience and outcome with the groups before them. Often these discussions lead to a profound shift in their perception of what happened during the immersive experience. For a group who has just concluded that the defendant is guilty, hearing that other groups before them have come to radically different conclusions (despite seeing the exact same evidence) can be very surprising. For a group who rather harmoniously reasoned themselves to a consensus, hearing that other groups split into opposing and entrenched camps can be equally eye-opening.

The participants' understanding is further shaped by weaving crucial insights from the psychology of individual and group decision making into the debrief. These insights help the participants to self-reflect on their own experience of immersion. This often results in participants "playing back" snippets of the immersive experience as they reflect on the moment when they made a decision, or when the group discussions took a particular turn.

This combination of experiencing something with ensuing self-reflection is known to be a prerequisite for experiential learning (Kolb, 2014), and one of the reasons why we made the reflection time of the debrief part of The Justice Syndicate: we wanted the piece to be a playful experience of real-life disagreements. Despite its reflective nature and break with the immersive piece, the debrief is not perceived by the participants as didactic, but rather appreciated by them as an additional means to make sense of the experience itself.

The debrief also provides also allows participants to decompress - it seems apt to borrow a term used to describe what divers do after they have been immersed in water (Huggins, 1992) to describe the process of transitioning audience members from a state of immersion to a state in which they can return to "real life." During the debrief, participants are invited to distance themselves from the arguments they were having during the piece and reflect on how they can apply what they have learned from the experience to their normal lives. This is part of fanSHEN's commitment to caring for audience members. In Virtual Futures, a Manifesto for Virtual Experiences, Scott-Stevenson writes:

"I mean 'care' through consideration of participant experience all the way from the introduction to and the exiting of and moments after the experience...if the story is distressing or unsettling it can take some time for the viewer to decompress afterwards, and being thrust straight back into a busy festival hall might not be appropriate. Ensuring that participants have an opportunity to reorient themselves is important." (Scot-Stevenson, 2019)

\section{Discussion}

With The Justice Syndicate, we have demonstrated that one possible way of inviting audience members to participate in a way that diminishes the fear of embarrassment (either experiencing or causing it) is for the invitation to be made by a machine. The project also demonstrates that it is possible to use iPads in combination with procedural authorship 
to create a situation in which audiences interact intensely and display high levels of agentive behaviour. Though we did not experiment with other forms of technology, we imagine that this invitation need not come from an iPad or other tablet. It could as easily come from a phone, computer or other machine. The crucial elements are that it must be something that cannot feel embarrassed, in front of which one is unlikely to feel embarrassed and that it must be something which cannot answer follow-up questions. Removing this fear of embarrassment increases the "horizon of participation" in audience members in a way that we believe may be replicable in other artworks.

The Justice Syndicate also demonstrates that the absence of live performers (itself made possible by the use of machines) can increase the level of agentive behaviour in audience members. However, as we discuss above, this does not inevitably lead to a corresponding increase in audience members' feeling of agency.

We have also demonstrated that it is possible to design interactive performances without live performers in a way that encourages flow in audience members by applying some of the principles outlined by Lindinger and colleagues (2013). As with all principles in creative practice, these can be fruitful both when they are followed and when they are deliberately broken. The Justice Syndicate differs significantly from The Letter Room (the project discussed by Lindinger et al., 2013) in how it applies the principles of flow. The Letter Room featured an alternation between active performers and active audiences (ibid.), whereas The Justice Syndicate applied them to a performance context without live performers

One area of The Justice Syndicate project that we do not yet have sufficient evidence about and which requires further research is the impact that the use of machine learning has on the experience of the participants. Joe McAlister writes:

"Machine learning is used within the Justice Syndicate platform to keep audience members from forming group consensus too early, thereby preventing a position where progressive discussion can't prevail." (McAlister, 2018)

We hope to publish the results of the effect this has (if any) when we have a larger dataset available from the performances of The Justice Syndicate that will take place in late 2019 and in 2020.

\section{Acknowledgements}

This work was supported by the Cultural Institute of King's College London, Near Now in Nottingham, The Centre for Research in Digital Storymaking at London South Bank University and the Digital Performance Research Group at London South Bank University.

\section{References}

Alier, L. (2019) The Justice Syndicate, Battersea Arts Centre, The Play's the Thing UK, 18 February 2019. Available from: https://theplaysthethinguk.com/2019/02/18/the-justicesyndicate-battersea-arts-centre/ [accessed 8 September 2019] 
Coney (2016) Adventure 1. Directed by Tassos Stevens.

https://coneyhq.org/2016/03/22/adventure-1-2016/ [accessed 8 September 2019]

Bishop, C (2012) Artificial Hells: Participatory Art and the Politics of Spectatorship. London and New York: Verso.

Breel, A. (2017). Conducting Creative agency: The Aesthetics and Ethics of Participatory Performance. PhD: University of Kent.

Calleja, 2011. In-Game - From Immersion to Incorporation. London and Cambridge, MA: MIT Press

Csikszentmihályi, M. (1997). Creativity: Flow and the Psychology of Discovery and Invention. New York: Harper Perennial.

Curtice, J. (1997) So How Well Did They Do? The Polls in the 1997 Election, Journal of the Market Research Society, 39(3), pp. 449-461

Dieli, 1989 The Usability Process: Working with Iterative Design Principles, IEEE Transactions in Professional Communication, 32:4) pp. 272-278. https://doi.org/10.1109/47.44539

Festinger, L. (1950). Informal social communication. Psychological Review, 57(5), 271-282.

Goffman, E. (1969) The presentation of the self in everyday life. Harmondsworth: Pelican

Huggins, K. (1992). Dynamics of decompression workshop. Course Taught at the University of Michigan.

Kolb, D. A. (2014). Experiential learning: Experience as the source of learning and development. FT press.

Lindinger, C., Mara,M., Obermaier, K., Aigner,R, Haring, R. \& Pauser, V. (2013) The (St)Age of Participation: audience involvement in interactive performances, Digital Creativity, 24(2), pp. 119-129. https://doi.org/10.1080/14626268.2013.808966

Machon, J. (2013). Immersive theatres: intimacy and immediacy in contemporary performance. Basingstoke: Palgrave Macmillan.

McAlister, J. (2018) The Justice Syndicate. Available from: https://joemcalister.com/thejustice-syndicate/ [accessed 1 August 2019]

McGonigal, J. (2011). Reality is Broken: Why Games Make Us Better and How They Can Change the World. New York: The Penguin Press.

Prensky, M. (2001) Digital Natives, Digital Immigrants Part 1, On the Horizon, 9 (5), pp. 1-6. https://doi.org/10.1108/10748120110424816

Ross, L., \& Ward, A. (1997). Naive realism in everyday life: Implications for social conflict and misunderstanding. In T. Brown, E. S. Reed \& E. Turiel (Eds.), Values and Knowledge (pp. 103135). Hillsdale, NJ: Erlbaum. 
Scott-Stevenson, J. (2019). Virtual Futures: A Manifesto for Immersive Experiences. Available from: http://i-docs.org/2019/03/14/virtual-futures-a-manifesto-for-immersive-experiences/ [accessed 20 September 2019)

Traynor, K. What is the Chance of Being Called for Jury Service? BBC News, 28 April. Available from: https://www.bbc.co.uk/news/uk-scotland-36140259 [accessed 1 August 2019]

White, G. (2013). Audience Participation in Theatre: Aesthetics of the Invitation. Basingstoke: Palgrave Macmillan. 